\title{
Le Livret d'opéra, textes réunis par Georges Zaragoza
}

\section{Véronique Montémont}

\section{(2) OpenEdition}

\section{Journals}

Édition électronique

URL : https://journals.openedition.org/studifrancesi/39507

DOI : 10.4000/studifrancesi.39507

ISSN : 2427-5856

Éditeur

Rosenberg \& Sellier

\section{Édition imprimée}

Date de publication : 1 décembre 2004

Pagination : 382

ISSN : 0039-2944

\section{Référence électronique}

Véronique Montémont, «Le Livret d'opéra, textes réunis par Georges Zaragoza », Studi Francesi [En ligne], 143 (XLVIII | II) | 2004, mis en ligne le 30 novembre 2015, consulté le 19 mai 2021. URL : http:// journals.openedition.org/studifrancesi/39507; DOI : https://doi.org/10.4000/studifrancesi.39507

Ce document a été généré automatiquement le 19 mai 2021.

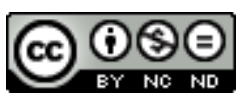

Studi Francesi è distribuita con Licenza Creative Commons Attribuzione - Non commerciale - Non opere derivate 4.0 Internazionale. 


\title{
Le Livret d'opéra, textes réunis par Georges Zaragoza
}

\author{
Véronique Montémont
}

\section{RÉFÉRENCE}

AA. VV. Le Livret d'opéra, textes réunis par GEORGES ZARAGOZA, Ivry-sur-Seine, Phénix

Editions, 2002, pp. 647.

1 Dans une étude ouvrant un volume qui regroupe 39 contributions, Elisabeth RALLODITICHE (pp. 11-15) commence par faire un sort aux préjugés selon lesquels le livret d'opéra est un genre intrinsèquement médiocre. Elle met en lumière la double portée des études librettologiques, qui se doivent d'analyser le texte en tant que tel, mais aussi comme lié à une entité plus vaste, le spectacle. Le livret n'est ni supérieur ni inférieur à la musique: les deux éléments se répondent pour fonder une commune entreprise de catharsis.

2 Neuf études intéressent directement la première moitié du XIX siècle. Violaine ANGER (pp. 157-187) montre ainsi que le XIX ${ }^{\mathrm{e}}$ siècle a été le temps d'une remise en question générique, tant du côté de la poésie que de la musique, dont l'évolution a eu une incidence sur l'écriture de livrets d'opéra. Elle s'intéresse en particulier à la métrique de Berlioz: la conception du vers, au départ assez classique, de ce compositeur, évolue vers une sensibilité au rythme et à la longueur des syllabes. Le vers s'allonge, s'assouplit, se transforme en période; la rime, liaison entre récitatif et air, constitue selon l'auteur l'ultime rempart contre un glissement du texte vers le poème en prose. Joseph-Marc BAILBÉ (pp. 189-199) met en évidence le caractère contrasté des points de vue des auteurs du XIXe siècle quant au livret d'opéra: Hugo n'y voit qu'une trame, alors que Berlioz est sensible à l'«idée poétique» du texte. L'étude compare le travail de Gounod et de Berlioz: dans le premier cas, le livret, trop riche, entrave la création du musicien, malgré son étroite collaboration avec les librettistes. Dans le second, Berlioz lui-même s'attelle à l'écriture d'après un poème de Virgile: l'auteur souligne la réussite, 
tant narrative que poétique du texte, qui devient une source de lyrisme donnant toute sa profondeur à la musique.

3 Laurence LE DIAGON-JACQUIN (pp. 201-208) analyse la valeur expressive et poétique de la «Chanson du Roi de Thulé» du Faust de Gounod et met en évidence son importance sur le plan de la structure narrative. Lise SABOURIN (pp. 209-222) compare le Cinq-Mars de Vigny et le livret de Poirson et Gallet sur lequel s'est appuyé Gounod. Elle montre que les modifications ont pour effet d'amplifier la dimension sentimentale au détriment du caractère politique de l'intrigue originale. La condensation des scènes, l'accent mis sur leur caractère spectaculaire et les équilibres vocaux sont autant de nécessités dramatiques justifiant ces adaptations.

4 Arnaud LASTER (pp. 223-240) étudie tour à tour quatre livrets tirés d'Angelo, tyran de Padoue de Hugo et met en évidence l'ampleur du spectre des variations: on passe d'une mise en relief de la passion amoureuse à une lecture politique, puis vériste, avant que le naturaliste Méré ne se rapproche de l'original, réintroduisant en particulier le grotesque occulté par ses prédécesseurs. Danièle GASIGLIA-LASTER (pp. 241-253) s'intéresse à la manière dont les différentes versions scéniques de Notre-Dame de Paris, des plus anciennes aux plus récentes, mettent en scène le personnage de Claude Frollo. La tension explosive qui existe entre sa condition de prêtre et l'amour qu'il voue à Esmeralda ne peut -censure oblige- s'exprimer sur scène aussi librement que dans le roman. Hugo lui-même, dans le livret écrit pour Louise Bertin, minore l'expression physique de la passion, tandis que l'adaptation espagnole fait de Frollo un bibliothécaire du roi. Il faut attendre la version contemporaine de Plamondon et Cocciante pour retrouver la noirceur et le déchirement originel du personnage. David A. Powell (pp. 255-274) retrace la genèse du livret hugolien de Notre-Dame de Paris et le compare au roman. Il étudie l'évolution du personnel romanesque et les modifications de l'intrigue, dictées par des impératifs scéniques et les contraintes de la censure. Puis il s'intéresse à la manière dont la femme est représentée dans cet opéra intitulé de manière éponyme La Esmeralda, qui pourtant ne valorise guère son héroöne.

C'est également sur cette adaptation que commence par se pencher Marie-Françoise CHRISTOUT (pp. 275-290), cette fois comme mettant en scène un personnage de gitane et de danseuse. Le chorégraphe Jules Perrot, en 1844, se souvient de ce trait pour livrer à son tour son adaptation, en confiant le rôle de Carmen à une prima ballerina. Sa version, interprétée par Carlotta Grisi, puis Fanny Ellsler, est un immense succès, salué de Londres à Moscou. D'autres versions chorégraphiques seront ensuite élaborées par Marius Petipa puis, au XXe siècle, par Roland Petit. Ces différentes adaptations peuvent être comparées aux versions successives de Carmen, car elles mettent en scène les mêmes thématiques: l'amour et la liberté, quel qu'en soit le prix. Fernande BASSAN (pp. 291-307) revient à son tour sur Carmen: elle souligne que, lors de sa parution en 1845, la nouvelle de Mérimée est passée presque inaperçue. La création de l'opéra de Bizet, sur un livret de Meilhac et Halévy, en 1875, a d'abord provoqué des réactions mitigées, dues à une pruderie exacerbée de la critique; mais les années suivantes ont consacré le triomphe absolu de cette oeuvre, qui a connu 2700 représentations à l'Opéra-Comique. 